\title{
Adult Acute T Cell Leukemia Presenting as Acute Renal Failure, Parotid Swelling and Loss of Vision
}

\author{
Usha $^{1}$, Deepa Santhosh ${ }^{1 *}$, Sandeep Kumar ${ }^{1}$, R. G. Singh ${ }^{2}$, Jai Prakash ${ }^{2}$ \\ ${ }^{1}$ Department of Pathology, Institute of Medical Sciences, Banaras Hindu University, Varanasi, India; \\ ${ }^{2}$ Department of Nephrology, Institute of Medical Sciences, Banaras Hindu University, Varanasi. India. \\ Email: ${ }^{\text {dr.dee.san@gmail.com }}$
}

Received June $14^{\text {th }}, 2013$; revised July $10^{\text {th }}, 2013$; accepted August $3^{\text {rd }}, 2013$

Copyright (C) 2014 Usha et al. This is an open access article distributed under the Creative Commons Attribution License, which permits unrestricted use, distribution, and reproduction in any medium, provided the original work is properly cited. In accordance of the Creative Commons Attribution License all Copyrights (c) 2014 are reserved for SCIRP and the owner of the intellectual property Usha et al. All Copyright (C) 2014 are guarded by law and by SCIRP as a guardian.

\section{ABSTRACT}

A rare case of $T$ cell acute lymphoblastic leukemia presenting with loss of vision, parotid swelling, hematuria and acute renal failure has been presented in a 40-year-old male. Acute $\mathbf{T}$ cell Lymphoblastic Leukemia should also be kept in differential diagnosis of hematuria, acute renal failure and loss of vision.

\section{KEYWORDS}

Acute Renal Failure; Acute T Lymphoblastic Leukemia; Adult; Hematuria; Parotid Gland Enlargement; Ocular Manifestation

\section{Introduction}

A patient with acute leukemia (AL) usually presents with features of fatigue, bone pain, anemia, neutropenia, fever, weight loss and thrombocytopenia leading to skin and mucosal bleeding $[1,2]$. A patient may also present with hepatosplenomegaly, lymphadenopathy, sore throat, bronchopneumonia, mediastinal mass, renal stone and sternal tenderness [2,3].

Acute renal failure and hematuria as a primary manifestation of acute leukemia are very rare. Acute renal failure is attributed to acute tubular necrosis, nephrotoxic drugs, urate nephropathy, gout, tumor lysis and malignant infiltration [4-8].

We are reporting a case of T-ALL which presented with sudden loss of vision, hematuria, bleeding nose, parotid swelling and renal failure. This case is being presented because of rarity.

\section{Case Report}

A 40-year-old male, presented with anorexia and sudden loss of vision 4 months back for which he consulted a private physician and treated, the particulars of the

\footnotetext{
${ }^{*}$ Corresponding author.
}

treatment were not available. About 2 months later he developed bleeding nose, parotid swelling, petechial hemorrhage, nausea, vomiting, swelling of eyelids and hematuria. He was again treated by private physician but symptoms were not relieved, for which he was referred to our nephrology department. Clinically the patient was suspected to have rapidly progressive renal failure due to vasculitis.

On examination, he had mild anemia, mild hepatosplenomegaly. In ultrasonography, there was hepatosplenomegaly, renomegaly and nephrolithiasis. His urine examination revealed $3+$ proteinuia, plenty of RBC's (100 - 150/HPF) and WBC (80 - 100/HPF) with raised blood urea, uric acid and serum creatinine. Hematological investigations revealed low hemoglobin (10.1 gm/dl), thrombocytopenia (platelet count 38,000/cumm) and high total count $\left(100 \times 10^{3} / \mu \mathrm{l}\right)$. His peripheral blood and bone marrow smears showed picture of acute lymphoblastic leukemia with mixture of small and large blast cells with scanty amount of cytoplasm, variable size and shape of nuclei with indentation, coarse chromatin and 1 - 2 nucleoli. Blast cells were negative for Sudan black and PAS stain (Figures 1 and 2).

Renal biopsy revealed only 3 to 4 glomeruli which 


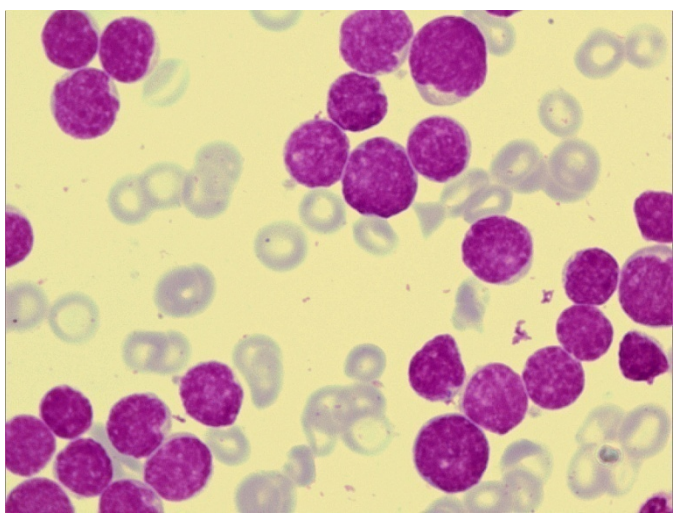

Figure 1. Acute T Lymphoblastic leukemia. Peripheral blood is showing mixture of small and large blasts. Both have coarse chromatin, 2 to 3 nucleoli and multiple notching in nuclei, and there is thrombocytopenia [Leishman's stain $\times 1000]$.

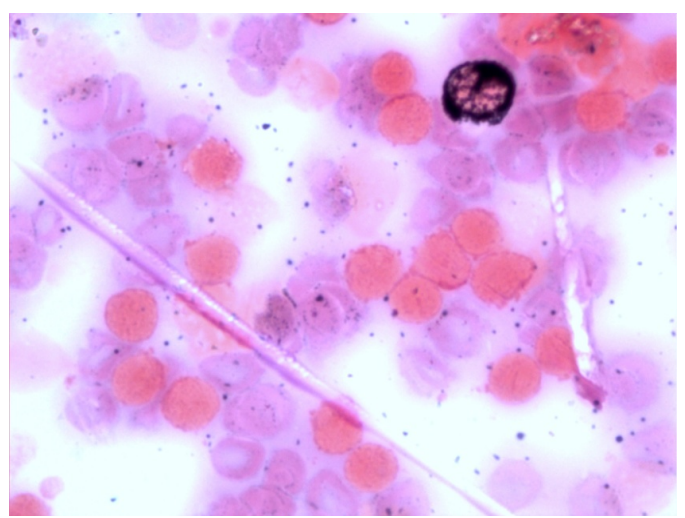

Figure 2. Sudan Black stain. Myelocyte is showing coarse black granules while lymphoblasts are sudan black negative [Sudan Black stain $\times \mathbf{1 0 0 0}$ ].

were normal in size and cellularity but with mild increase of mesangial matrix was noted. Tubules revealed swelling of tubular epithelial cells, clear appearing cytoplasm and vesicular nuclei and necrosis. Some tubules contained immature cells. Interstitium was heavily infilterated with large uniform size immature lymphocyte like cell with very scanty non visible cytoplasm and dark nuclei with coarse and opened chromatin (Figures 3 and 4). Blood vessels did not show any abnormality.

Immunophenotyping of leukemic cells on kidney biopsy revealed that immature cells were negative for myeloperoxidase (MPO) (Figure 5), CD13, CD19, CD20 and CD79a but almost all the cells were strongly positive for CD3 antigen (Figure 6) and CD7. Ultimately patient was diagnosed as a case of acute $\mathrm{T}$ cell Lymphoblastic Leukemia and chemotherapy was started but he died after 10 days of diagnosis.

\section{Discussion}

Acute renal failure (ARF) and hematuria may occur in

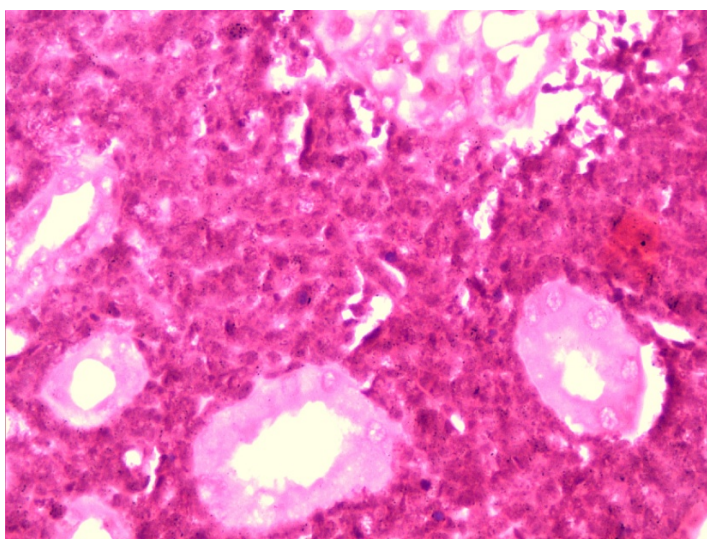

Figure 3. Acute $\mathbf{T}$ cell lymphoblastic leukemia. Immature cells are large, irregular, have fuzzy outline infiltrating whole interstitium. Focal necrosis and proximal tubules are seen $[H \& E \times 400]$.

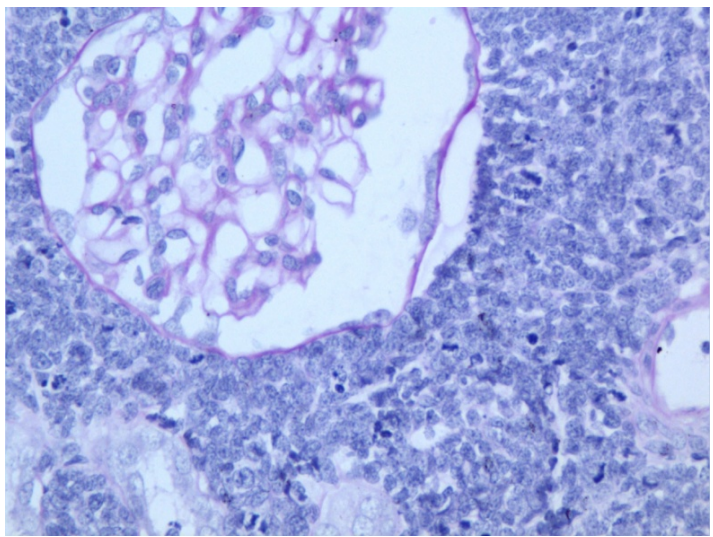

Figure 4. PAS stain of same case. Glomerulus is enlarged but normal in cellularity. Malignant lymphocytes are PAS negative [PAS stain $\times 400]$.

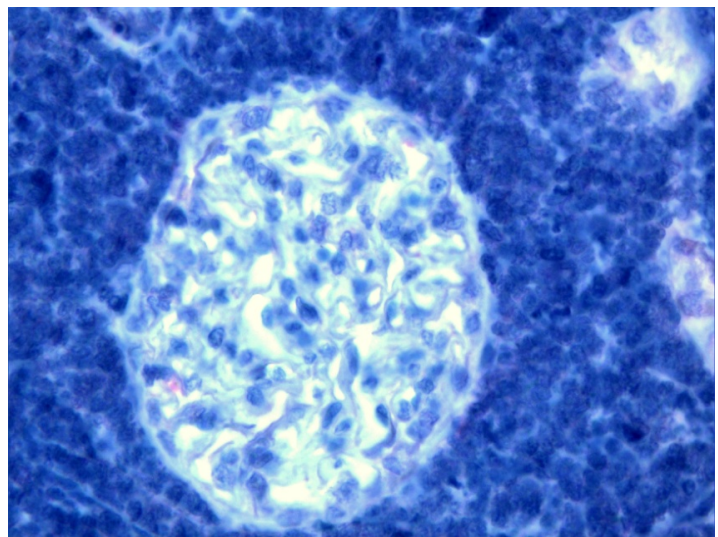

Figure 5. Immunocytochemical staining for MPO. Leukemic cells are negative for MPO [APAAP stain $\times 400$ ].

both acute myeloid leukemia (AML) and acute lymphoblastic leukemia (ALL) [6,8]. Renal failure is a rare manifestation of acute leukemia. A study [8] reported a case of AML who presented with acute renal failure, 


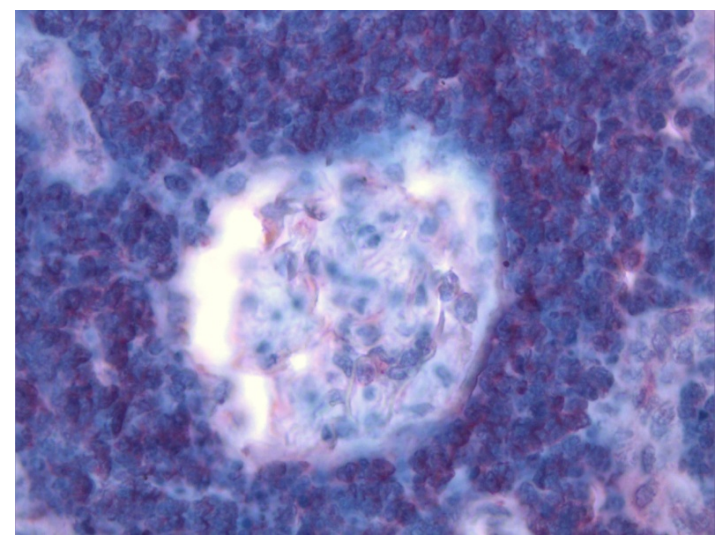

Figure 6. immunocytochemical staining for CD 3 in T ALL. It shows that glomeruli are normal but interstitial leukemic cells are showing diffuse membranous and cytoplasmic red staining. [Alkaline Phosphatase AntiAlkaline phosphatase stain $\times 400]$

bilateral ureteral obstruction, and pelvic mass. His peripheral blood showed 63\% myeloblast. This patient died on 17th day after chemotherapy.

Another study [9] reported a case of ALL who presented with ARF and enlargement of kidney and liver. Histopathology of kidney and liver showed infiltration by lymphoblasts.

Suriya and Aleem 2010 described 2 cases of AL in which one was Pre B ALL and another was of AML M4. Both presented with gross hematuria, loin pain, low grade fever and thrombocytopenia. Both cases showed remission after therapy.

Our case is a rare by constellation of manifestations, initially by loss of vision followed by parotid swelling, epistaxis, petechial hemorrhage, hematuria and then acute renal failure. Delayed appearance of ALL may occur. One study [6] also reported a case of ALL in a child who initially presented as hemolytic uremic syndrome and after one month he developed typical features of ALL.

Patient of AL may also present with Bell's palsy and renal enlargement along with renal failure [10].

Parotid gland enlargement in ALL is very rare. Agarwal et al. 2005 [11] reported 2 cases of B ALL in 23 year and 15 month old boy who presented with pallor, hepatosplenomegaly, lymphadenopathy, thrombocytopenia with parotid gland enlargement. Lymphoblasts in peripheral blood were CD10 positive.

Acute T ALL is still rare disease. It accounts for $15 \%$ $20 \%$ cases of ALL. The blasts are PAS negative but acid phosphatase CD3, CD2 and CD7 are positive. T-ALL has got high incidence of CNS manifestation and mediastinal mass and have poor prognosis [2].

Sudden loss of vision was the primary and initial manifestation of this case. Leukemia may involve ocular tissue either by direct infiltration of retina or vitreous, hemorrhage, ischemia or toxicity due to various chemotherapeutic agents, infection due to immunosuppression or direct leukemic infiltration [12]. In our case hemorrhage was one of the causes. Since no biopsy was done it is difficult to predict direct infiltration.

\section{Conclusion}

Thus we conclude that T-ALL is to be kept as a cause of ARF with loss vision or parotid swelling in any age group.

\section{REFERENCES}

[1] O. M. Suriya and A. Aleem, "Frank Hematuria as the Presentation Feature of Acute Leukemia,” Saudi Journal of Kidney Diseases and Transplantation, Vol. 21, No. 5, 2010, pp. 940-942.

[2] T. Singh, “Atlas and Text of Hematology,” Avichal Publishing Company, New Delhi, 2010, p. 136.

[3] J. Trachsler, A. Gaspert, M. Previsdomini, R. P. Wuthrich and T. Fehr, "Massive Uric Acid Nephrolithiasis with Progressive Renal Failure Due to Spontaneous Tumour Lysis Syndrome,” NDT Plus, Vol. 1, No. 5, 2008, pp. 307-309. http://dx.doi.org/10.1093/ndtplus/sfn133

[4] N. Gilboa, G. M. Lum and R. E. Urizar, "Early Renal Involvement in Acute Lymphoblastic Leukemia and NonHodgkin's Lymphoma in Children,” Journal of Urology, Vol. 129, No. 2, 1983, pp. 364-367.

[5] K. P. Harris, J. M. Hattersley, J. Feehally and J. Walls, "Acute Renal Failure Associated with Haematological Malignancies: A Review of 10 Years Experience,” European Journal of Haematology, Vol. 47, No. 2, 1991, pp. 119-122.

http://dx.doi.org/10.1111/j.1600-0609.1991.tb00133.x

[6] G. Martini, R. Dall’Amico, L. Murer, G. Montini, A. D'Avino and G. Zacchello, "Hemolytic-Uremic Syndrome as a Presenting form of Acute Lymphocytic Leukemia," Annals of Hematology, Vol. 79, No. 8, 2000, pp. 452-454. http://dx.doi.org/10.1007/s002770000174

[7] H. H. Hsu, Y. L. Chan and C. C. Huang, "Acute Spontaneous Tumor Lysis Presenting with Hyperuricemic Acute Renal Failure: Clinical Features and Therapeutic Approach,” Journal of Nephrology, Vol. 17, No. 1, 2004, pp. 50-56.

[8] S. Z. Usmani, Z. Shahid, H. Saleh and K. A. Nasser, "Myeloid Sarcoma Presenting with Acute Renal Failure and Bilateral Ureteral Obstruction: A Case Report and Review of the Literature," American Journal of the Medical Sciences, Vol. 334, No. 2, 2007, pp. 136-138 http://dx.doi.org/10.1097/MAJ.0b013e31812e978b

[9] Y. Basaran, S. Sayin, G. Erdem, O. Nevruz and A. U. Ural, “A Rare Initial Manifestation of Acute Lymphocytic Leukemia: Bilaterally Enlarged Kidneys and Liver,” Internal Medicine, Vol. 48, No. 17, 2009, pp. 1541-1544. http://dx.doi.org/10.2169/internalmedicine.48.2395

[10] W. M. Suh, Z. A. Wainberg, S. de Vos, A. H. Cohen, I. Kurtz and M. K. Nguyen, “Acute Lymphoblastic Leuke- 
mia Presenting as Acute Renal Failure,” Nature Clinical Practice Nephrology, Vol. 3, No. 2, 2007, pp. 106-110. http://dx.doi.org/10.1038/ncpneph0400

[11] V. Agarwal, R. Mondal, N. Krishnani and S. Nityanand, "Parotid Gland Enlargement as a Presenting Manifestation of Acute Lymphoblastic Leukemia,” JK Science, Vol.
7, No. 3, 2005, pp. 167-168.

[12] T. Sharma, J. Grewal, S. Gupta and P. I. Murray, “Ophthalmic Manifestations of Acute Leukaemias: The Ophthalmologist's Role,” Eye, Vol. 18, No. 7, 2004, pp. 663672. http://dx.doi.org/10.1038/sj.eye.6701308

\section{Abbreviations}

AL-Acute Leukemia

ALL_-Acute Lymphoblastic Leukemia

AML_-Acute Myeloid Leukemia

RBC-Red Blood Cells

WBC-White Blood Cells

PAS-Periodic Acid Schiff

CD-Cluster Differentiation

ARF_-Acute Renal Failure

MPO-Myeloperoxidase

HPF_-High Power Field

APAAP_Alkaline Phosphatase AntiAlkaline Phosphatase Stain

$\mathrm{H} \& \mathrm{E}-$ Hematoxylin and Eosin

CNS-Central Nervous System 